Article

\title{
Thermal Behavior of Mixed Plastics at Different Heating Rates: I. Pyrolysis Kinetics
}

\author{
Ibrahim Dubdub $\mathbb{( 1 )}$ and Mohammed Al-Yaari * $\mathbb{C}$ \\ Chemical Engineering Department, King Faisal University, P.O. Box 380, Al-Ahsa 31982, Saudi Arabia; \\ idubdub@kfu.edu.sa \\ * Correspondence: malyaari@kfu.edu.sa; Tel.: +966-13-589-8583
}

Citation: Dubdub, I.; Al-Yaari, M. Thermal Behavior of Mixed Plastics at Different Heating Rates: I. Pyrolysis Kinetics. Polymers 2021, 13, 3413. https://doi.org/10.3390/ polym13193413

Academic Editor: Shazed Aziz

Received: 14 September 2021

Accepted: 29 September 2021

Published: 5 October 2021

Publisher's Note: MDPI stays neutral with regard to jurisdictional claims in published maps and institutional affiliations.

Copyright: (c) 2021 by the authors. Licensee MDPI, Basel, Switzerland. This article is an open access article distributed under the terms and conditions of the Creative Commons Attribution (CC BY) license (https:/ / creativecommons.org/licenses/by/ $4.0 /)$.

\begin{abstract}
The amount of generated plastic waste has increased dramatically, up to 20 times, over the past 70 years. More than $50 \%$ of municipal plastic waste is composed of polystyrene (PS), polypropylene (PP), and low-density polyethylene (LDPE) products. Therefore, this work has developed a kinetic model that can fully describe the thermal decomposition of plastic mixtures, contributing significantly towards the efficiency of plastic waste management and helping to save the environment. In this work, the pyrolysis of different plastic mixtures, consisting of PP, PS, and LDPE, was performed using a thermogravimetric analyzer (TGA) at three different heating rates $(5,20$, and $40 \mathrm{~K} / \mathrm{min})$. Four isoconversional models, namely Friedman, Flynn-Wall-Qzawa (FWO), Kissinger-Akahira-Sunose (KAS), and Starink, have been used to obtain the kinetic parameters of the pyrolysis of different plastic mixtures with different compositions. For the equi-mass binary mixtures of PP and PS, the average values of the activation energies were 181, $144 \pm 2 \mathrm{~kJ} / \mathrm{mol}$ obtained using the Freidman and integral (FWO, KAS, and Starink) models, respectively. However, higher values were obtained for the equi-mass ternary plastic mixtures of PP, PS, and LDPE (Freidman: $255 \mathrm{~kJ} / \mathrm{mol}$, FWO: $222 \mathrm{~kJ} / \mathrm{mol}, \mathrm{KAS}: 223 \mathrm{~kJ} / \mathrm{mol}$, and Starink: $222 \mathrm{~kJ} / \mathrm{mol}$ ). The most suitable reaction mechanisms were obtained using the Coats-Redfern model. The results confirm that the most controlling reaction mechanisms obey the first-order (F1) and the third-order (F3) reactions for the pyrolysis of the equi-mass binary (PS and PP) and equi-mass ternary (PS, PP, and LDPE) mixtures, respectively. Finally, the values of the pre-exponential factor (A) were obtained using the four isoconversional models and the linear relationship between $\ln \mathrm{A}$ and the activation energy was confirmed.
\end{abstract}

Keywords: pyrolysis; plastic waste; activation energy; thermogravimetric analyzer (TGA); kinetics; reaction mechanism

\section{Introduction}

Plastic waste management must be considered as a key priority. The amount of the generated plastic waste has increased in the past 70 years by more than 20 times. In addition, the annual production rate of plastic is much higher than that of plastic recycling; thus, most plastic waste is either disposed of in landfills or incinerated [1]. Moreover, the recycling process has some limitations due to the availability of some additives used to improve the properties of plastic and to meet application needs [2]. Furthermore, plastic production consumes almost $4 \%$ of the global oil production rate [3]. Thus, plastic waste is one of the main sources of contamination, with serious consequences for environmental sustainability.

Due to its moderate operating temperatures and clean products, pyrolysis is a preferable option to recover energy from municipal plastic waste (MPW) as chemicals and fuels [4-8].

MPW mainly contains low-density polyethylene (LDPE), high-density polyethylene (HDPE), polypropylene (PP), polystyrene (PS), and polyethylene terephthalate (PET) but 
with different compositions. Therefore, extensive work has been performed to obtain the kinetic parameters of pure and mixed plastics.

Wu et al. (1993) [9] studied the pyrolysis of six polymers HDPE, LDPE, PP, PS, polyvinylchloride (PVC), and acrylonitrile butadiene styrene (ABS) of MPS with their mixtures using a thermogravimetric analyzer (TGA) at heating rates of 1,2 , and $5.5 \mathrm{~K} / \mathrm{min}$. Insignificant interaction between these polymers was reported during the pyrolysis process.

Chowlu et al. (2009) [10] studied the pyrolysis behavior of a mixture of PP and LDPE at five different mixture compositions and heating rates. The Vyazovkin (VYA) model, as one of the model-free techniques, was used to investigate the effect of conversion on activation energy. Three different zones were reported: slow at low conversion range, slightly high at the middle range of conversion, and strongly high at high conversion range. Therefore, the best mixture weight ratio of PP/LDPE, with the lowest activation energy, was reported as $65 / 35$.

Aboulkas et al. (2010) [11] studied the reaction mechanism of the thermal decomposition of HDPE, LDPE and PP using the Coats-Redfern and Criado methods. While the contracting sphere model best fit the HDPE and LDPE data, the contracting cylinder model worked well with the PP data.

Diaz Silvarrey and Phan (2016) [1] investigated the reaction mechanism of the thermal decomposition of five different polymers: HDPE, LDPE, PP, PS, and PET using TGA and MATLAB. Kissinger-Akahira-Sunose (KAS), Malek, and linear model fitting methods were used to obtain the mechanism of the pyrolysis, which was checked using the experimental data obtained from TGA tests. Four heating rates $(5,10,20$, and $40 \mathrm{~K} / \mathrm{min})$, covering the temperature range of $30-700{ }^{\circ} \mathrm{C}$, were employed. All the polymer samples were reported to have one step of decomposition, moving to a higher temperature with the order: $\mathrm{PS}<\mathrm{PET}<\mathrm{PP}<\mathrm{LDPE}<\mathrm{HDPE}$. Using the KAS method, the following values of activation energy and pre-exponential factor were reported: (PS: $192.61 \mathrm{KJ} / \mathrm{mol}, 5.52 \mathrm{E} 14$ 1/K), (HDPE: $202.40 \mathrm{KJ} / \mathrm{mol}$, 3.23E16 1/K), (LDPE: $267.61 \mathrm{KJ} / \mathrm{mol}, 7.86 \mathrm{E} 19$ 1/K), and (PP: $261.22 \mathrm{KJ} / \mathrm{mol}, 3.03 \mathrm{E} 21$ 1/K).

Yu et al. (2016) [12] conducted a helpful review on the thermal decomposition of PVC mixed with different polymers (PP, polyethylene (PE), and PS). The interaction between polymers was found to be mainly dependent on the nature of the mixed polymers.

Anene et al. (2018) [13] studied the thermal degradation of different compositions of LDPE/PP mixtures. The degradation started at a lower temperature for the LDPE/PP mixture than the pure LDPE, proving an interaction between the polymers.

Mumbach et al. (2019) [14] studied the thermal decomposition of MPW by a TGA under inert conditions at four heating rates $(5,10,20$, and $30 \mathrm{~K} / \mathrm{min})$. The feedstock of the MPW included 51.85\% PP, 17.28\% LDPE, 7.41\% HDPE, 17.28\% PVC, PET, and PS, and 6.18\% lignocellulosic. While the kinetic parameters, such as activation energy, were estimated by four isoconversional (FWO, KAS, Starink, and VYA) models, the reaction mechanisms were obtained by the Criado master plots. The following three main reaction stages were identified: the decomposition of holocellulose with the first stage of the decomposition of PVC (dichlorination); the decomposition of PS and some adhesive acrylic-based resins; the thermal decomposition of PP, LDPE, and HDPE, and the second stage of the decomposition of PVC.

Recently, Dubdub and Al-Yaari (2020) [15] investigated the co-pyrolysis process of mixed polymers (PS/PP/HDPE/LDPE) at a single heating rate $(60 \mathrm{~K} / \mathrm{min})$. The CoatsRedfern and Criado models were used to obtain the kinetic parameters and the most suitable reaction mechanism. In addition, a synergetic effect was observed for some mixtures and compositions.

Although different kinetic investigations have been performed for pure and mixed plastics, most are inaccurate and inconsistent because of their simple assumed mechanisms or experiment conditions (single heating rate). Therefore, this investigation has developed a kinetic model that fully describes the thermal behavior of the pyrolysis of mixed plastics, comprising PP, PS, and LDPE, at different heating rates. In addition, the triple 
kinetic parameters (activation energy, pre-exponential factor, and most suitable controlling mechanism/s) have been determined.

\section{Materials and Methods}

\subsection{Materials}

Pellets of PP, PS, and LDPE, supplied by Ipoh SY Recycle Plastic Sdn. Bhd., Perak, Malaysia, were ground into powder. Then, $10 \mathrm{mg}$ of each powder sample was used throughout the study. Proximate and ultimate analysis was performed to characterize the polymer samples; these data are presented in Table 1. Details of both tests are described elsewhere [15].

Table 1. Proximate and ultimate analysis of the used plastics.

\begin{tabular}{cccccccc}
\hline \multirow{2}{*}{ Plastic } & \multicolumn{2}{c}{ Proximate Analysis, wt $\%$} & \multicolumn{4}{c}{ Ultimate Analysis, wt $\%$} \\
\cline { 2 - 7 } & Moisture & Volatile & Ash & C & H & N & S \\
\hline PP & 0.08 & 99.63 & 0.29 & 85.00 & 14.73 & 0.04 & 0.23 \\
PS & 0.24 & 99.59 & 0.17 & 90.47 & 9.43 & 0.00 & 0.08 \\
LDPE & 0.20 & 99.65 & 0.15 & 83.00 & 16.75 & 0.00 & 0.25 \\
\hline
\end{tabular}

\subsection{Thermal Decomposition Experiments}

Pyrolysis of different mixtures of PP, PS, and LDPE with different compositions at three different heating rates $(5,20$, and $40 \mathrm{~K} / \mathrm{min})$ were performed using the thermogravimetric analyzer (TGA-7), manufactured by PerkinElmer, Shelton, CT, USA, and equipped with a high precision weighing balance. Thermal decomposition experiments were conducted under $\mathrm{N}_{2}(99.999 \%)$ gas flowing at $100 \mathrm{~cm}^{3} / \mathrm{min}$. The experimental matrix is presented in Table 2 .

Table 2. Experimental matrix.

\begin{tabular}{ccccc}
\hline & \multirow{2}{*}{$\begin{array}{c}\text { Heating Rate } \\
\text { TK/min) }\end{array}$} & PP & Weight $\%$ \\
\cline { 3 - 5 } & 5 & 50 & 50 & LDPE \\
\hline 1 & 20 & 50 & 50 & 0 \\
2 & 40 & 50 & 50 & 0 \\
3 & 5 & 33.3 & 33.3 & 0 \\
4 & 20 & 33.3 & 33.3 & 33.3 \\
5 & 40 & 33.3 & 33.3 & 33.3 \\
6 & & & \\
\hline
\end{tabular}

\subsection{Kinetic Theory}

The reaction rate $\left(\frac{d \alpha}{d t}\right)$ of the pyrolysis of PVC can be expressed as follows:

$$
\begin{gathered}
\frac{d \alpha}{d t}=K(T) \times f(\alpha) \\
\alpha=\frac{w_{o}-w}{w_{o}-w_{f}}
\end{gathered}
$$

where:

$\alpha$ : is the reaction conversion;

$t$ : is time (min);

$K:$ is the reaction rate constant $\left(\mathrm{K}^{-1}\right)$, expressed as: $K(T)=A \exp \left(-\frac{E_{a}}{R T}\right)$;

$A$ : is a pre-exponential factor $\left(\mathrm{K}^{-1}\right)$;

$E_{a}$ : is the activation energy $(\mathrm{kJ} / \mathrm{mol})$;

$R:$ is the universal gas constant $(8.314 \mathrm{~J} / \mathrm{mol} . \mathrm{K})$;

$T$ : is temperature (K);

$w_{0}$ : is the initial weight of the sample used for the experiment; 
$w:$ is the instantaneous weight of the sample (at time $t$ );

$w_{f}:$ is the weight left of the sample at the end of the experiment.

For non-isothermal pyrolysis, the heating rate $(\beta)$ can be defined as $\beta=\frac{d T}{d t}$, and thus the reaction rate can be written as:

$$
\beta \frac{d \alpha}{d T}=A \exp \left(-\frac{E_{a}}{R T}\right) \times f(\alpha)
$$

The development of a high-efficient kinetic model that can describe the pyrolysis process requires obtaining kinetic parameters accurately. Using TGA data at different heating rates, the activation energy can be obtained using isoconversional (model-free) models such as the Freidman (Equation (4)), FWO (Equation (5)), KAS (Equation (6)), and Starink (Equation (7)) models. These four models are among the most widely used models and thus have been used in this investigation.

$$
\begin{gathered}
\ln \left(\beta \frac{d \alpha}{d T}\right)=\ln [A f(\alpha)]-\frac{E_{a}}{R T} \\
\ln (\beta)=\ln \frac{A E_{a}}{R g(\alpha)}-5.331-1.052 \frac{E_{a}}{R T} \\
\ln \left(\frac{\beta}{T^{2}}\right)=\ln \frac{A R}{E_{a} g(\alpha)}-\frac{E_{a}}{R T} \\
\ln \left(\frac{\beta}{T^{1.92}}\right)=\text { Constant }-1.0008 \frac{E_{a}}{R T}
\end{gathered}
$$

However, model-fitting methods, such as the Coats-Redfern model (Equation (8)), can be used to obtain kinetic parameters based on a hypothetical reaction model.

$$
\ln \left[\frac{g(\alpha)}{T^{2}}\right]=\ln \left[\frac{A R}{\beta E}\right]-\frac{E_{a}}{R T}
$$

where $f(\alpha)$ and $g(\alpha)$ are the differential and integral forms of the conversion-dependent term, respectively. Table 3 shows different commonly used solid-state thermal reaction mechanisms along with the $f(\alpha)$ and $g(\alpha)$ expressions.

In this work, the activation energy values were obtained using four isoconversional models (Equations (4)-(7)) and the TGA experimental data. These models are independent of the reaction mechanism, and they are among the most used models. The most suitable reaction mechanism was determined by the Coats-Redfern model (Equation (8)). After this, the values of the pre-exponential factor were calculated using the isoconversional models' equations. Finally, the linear relationship between $\ln (A)$ and $E_{a}$ was checked.

Table 3. Solid-state thermal reaction mechanisms.

\begin{tabular}{lcc}
\hline Reaction Mechanism & $f(\alpha)$ & $g(\boldsymbol{\alpha})$ \\
\hline Reaction-Order Models & & \\
First order (F1) & $1-\alpha$ & $-\ln (1-\alpha)$ \\
Second order (F2) & $(1-\alpha)^{2}$ & $(1-\alpha)^{-1}-1$ \\
Third order (F3) & $(1-\alpha)^{3}$ & {$\left[(1-\alpha)^{-1}-1\right] / 2$} \\
Diffusion Models & $1 / 2 \alpha^{-1}$ & $\alpha^{2}$ \\
One-dimensional (D1) & {$[-\ln (1-\alpha)]^{-1}$} & $(1-\alpha) \ln (1-\alpha)+\alpha$ \\
Two-dimensional (D2) & $3 / 2\left[1-(1-\alpha)^{1 / 3}\right]^{-1}$ & {$\left[1-(1-\alpha)^{1 / 3}\right]^{2}$} \\
Three-dimensional (D3) & & \\
\hline
\end{tabular}


Table 3. Cont.

\begin{tabular}{lcc}
\hline Reaction Mechanism & $f(\boldsymbol{\alpha})$ & $\boldsymbol{g}(\boldsymbol{\alpha})$ \\
\hline Nucleation Models & & \\
Two-dimensional nucleation (A2) & $2(1-\alpha)[-\ln (1-\alpha)]^{1 / 2}$ & {$[-\ln (1-\alpha)]^{1 / 2}$} \\
Three-dimensional nucleation (A3) & $3(1-\alpha)[-\ln (1-\alpha)]^{1 / 3}$ & {$[-\ln (1-\alpha)]^{1 / 3}$} \\
Four-dimensional nucleation (A4) & $4(1-\alpha)[-\ln (1-\alpha)]^{1 / 4}$ & {$[-\ln (1-\alpha)]^{1 / 4}$} \\
Geometrical Contraction Models & 1 & $\alpha$ \\
Prout-Tompkins (R1) & $2(1-\alpha)^{1 / 2}$ & $1-(1-\alpha)^{1 / 2}$ \\
Contracting cylinder (R2) & $3(1-\alpha)^{1 / 3}$ & $1-(1-\alpha)^{1 / 3}$ \\
Contracting sphere (R3) & $2 \alpha^{1 / 2}$ & $\alpha^{1 / 2}$ \\
Power Law Models & $3 \alpha^{2 / 3}$ & $\alpha^{1 / 3}$ \\
Power law (P2) & $4 \alpha^{3 / 4}$ & $\alpha^{1 / 4}$ \\
Power law (P3) & & \\
Power law (P4) & & \\
\hline
\end{tabular}

\section{Results and Discussion}

\subsection{Thermogravimetric Analysis}

The thermogravimetric (TG) and derivative-thermogravimetric (DTG) curves of the pyrolysis of mixed polymer samples are presented in the figures below. Although Figure 1 represents data of the equi-mass binary mixture of PP and PS, Figure 2 shows the TGA data of the equi-mass ternary mixture of PP, PS, and LDPE at different heating rates. Generally, as reported for individual plastics in previous works [15-17], thermograms of all mixtures have a similar inverted S-shape. However, they were shifted to higher temperatures as the heating rate increased (i.e., a faster heating rate implies a small weight loss at specific temperatures). In addition, as the heating rate increases, the change in the rate of weight loss increases, thus producing higher DTG values. Furthermore, complete pyrolysis ( $100 \%$ weight loss) of all tests has been observed, which reflects the purity of the polymer samples when ash content is negligible (see Table 1). Table 4 presents the characteristic decomposition temperatures (i.e., the onset, peak, and final decomposition temperatures).

These figures clearly show that there was only one main reaction region for the pyrolysis of mixed polymers. These findings are in full agreement with different published data $[12,13]$.

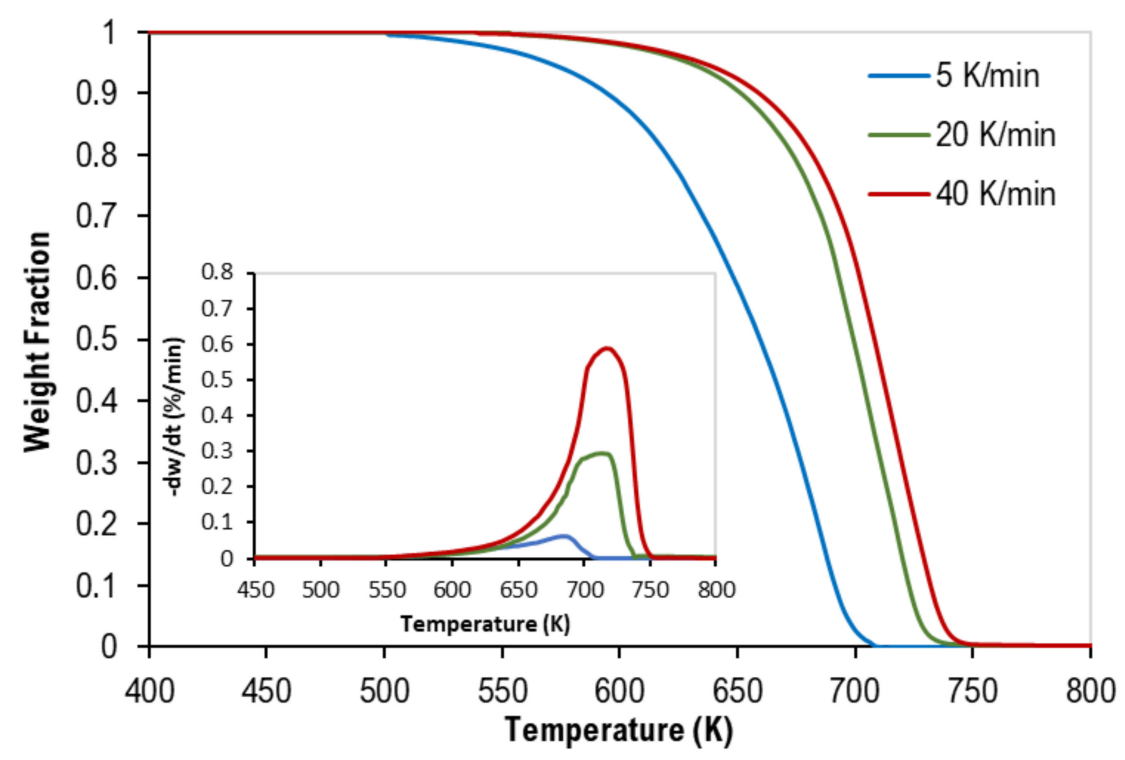

Figure 1. Thermogravimetric (TG) curves of equi-mass binary mixtures of PP and PS (Tests 1-3). Inset: corresponding derivative thermogravimetric (DTG) curves. 


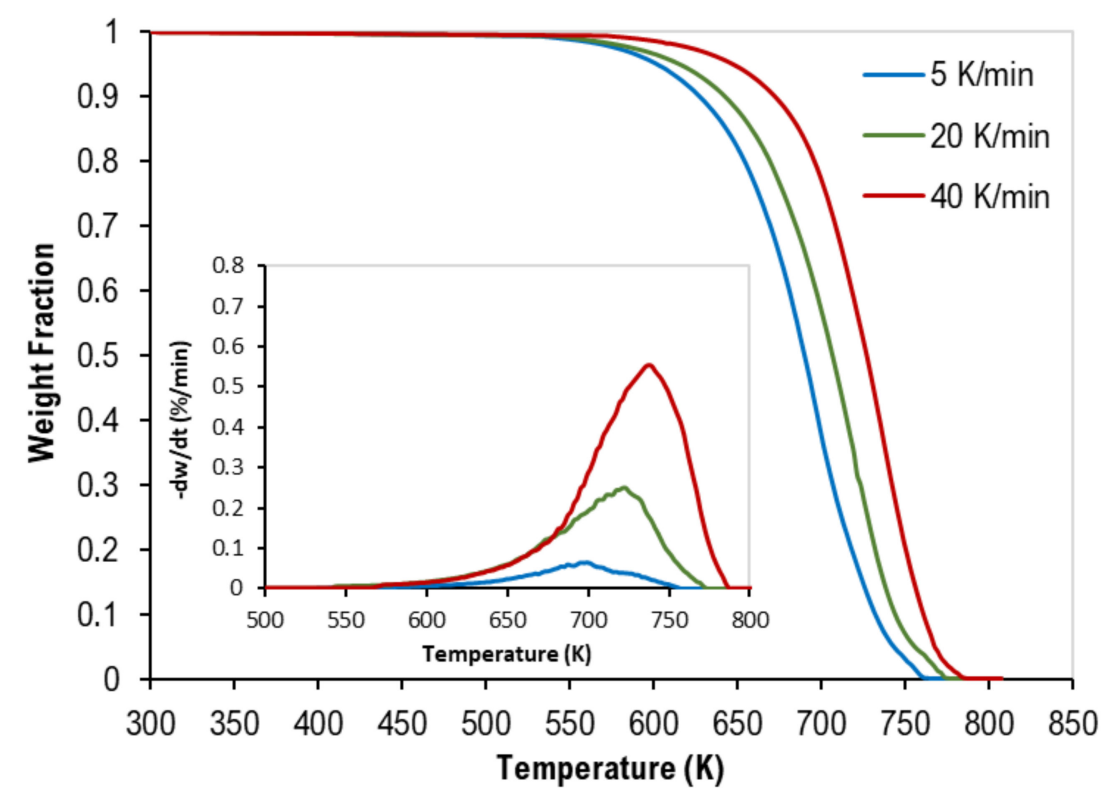

Figure 2. Thermogravimetric (TG) curves of equi-mass ternary mixtures of PP, PS, and LDPE (Tests 4-6). Inset: corresponding derivative thermogravimetric (DTG) curves.

Table 4. Onset, peak, and final decomposition temperatures.

\begin{tabular}{|c|c|c|c|c|c|c|c|}
\hline \multirow{2}{*}{ Test No. } & \multirow{2}{*}{$\begin{array}{l}\text { Heating Rate } \\
\text { (K/min) }\end{array}$} & \multicolumn{3}{|c|}{ Weight \% } & \multirow{2}{*}{$\begin{array}{c}\text { Onset } \\
\text { Temp. (K) }\end{array}$} & \multirow{2}{*}{$\begin{array}{l}\text { Peak Temp. } \\
\text { (K) }\end{array}$} & \multirow{2}{*}{$\begin{array}{l}\text { Final Temp. } \\
\text { (K) }\end{array}$} \\
\hline & & PP & PS & LDPE & & & \\
\hline 1 & 5 & 50 & 50 & 0 & 500 & 686 & 708 \\
\hline 2 & 20 & 50 & 50 & 0 & 550 & 720 & 734 \\
\hline 3 & 40 & 50 & 50 & 0 & 560 & 730 & 750 \\
\hline 4 & 5 & 33.3 & 33.3 & 33.3 & 540 & 690 & 760 \\
\hline 5 & 20 & 33.3 & 33.3 & 33.3 & 610 & 720 & 775 \\
\hline 6 & 40 & 33.3 & 33.3 & 33.3 & 630 & 735 & 785 \\
\hline
\end{tabular}

\subsection{Activation Energy Determination}

As mentioned earlier, four isoconversional models were used to obtain the activation energy, which is the main kinetic parameter by which the optimum mixture composition can be recommended. The linear regression lines of binary equi-mass PP and PS mixtures (tests 1-3) at different conversions ranging from 0.1 to 0.9, using the Freidman, FWO, KAS, and Starink models, are shown in Figure 3. Figure 4 illustrates the lines of ternary equi-mass in PP, PS, and LDPE mixtures (tests 4-6) at the same range of conversion. In addition, the obtained values of activation energy by each model at different conversions for binary and ternary equi-mass mixtures are presented in Tables 5 and 6, respectively.

Generally, the obtained values of activation energy, from non-isothermal TGA data, by model-free methods are more reliable than those obtained by model-fitting models since the model-free values are mechanism-independent. Activation energy values are obtained as a function of reaction conversion, which may help to show multi-reaction complexity [18]. As the conversion increases, the value of the activation energy also increases [19] (see Figure 5); in this case, the average values can be utilized when industrial processes are modelled. 

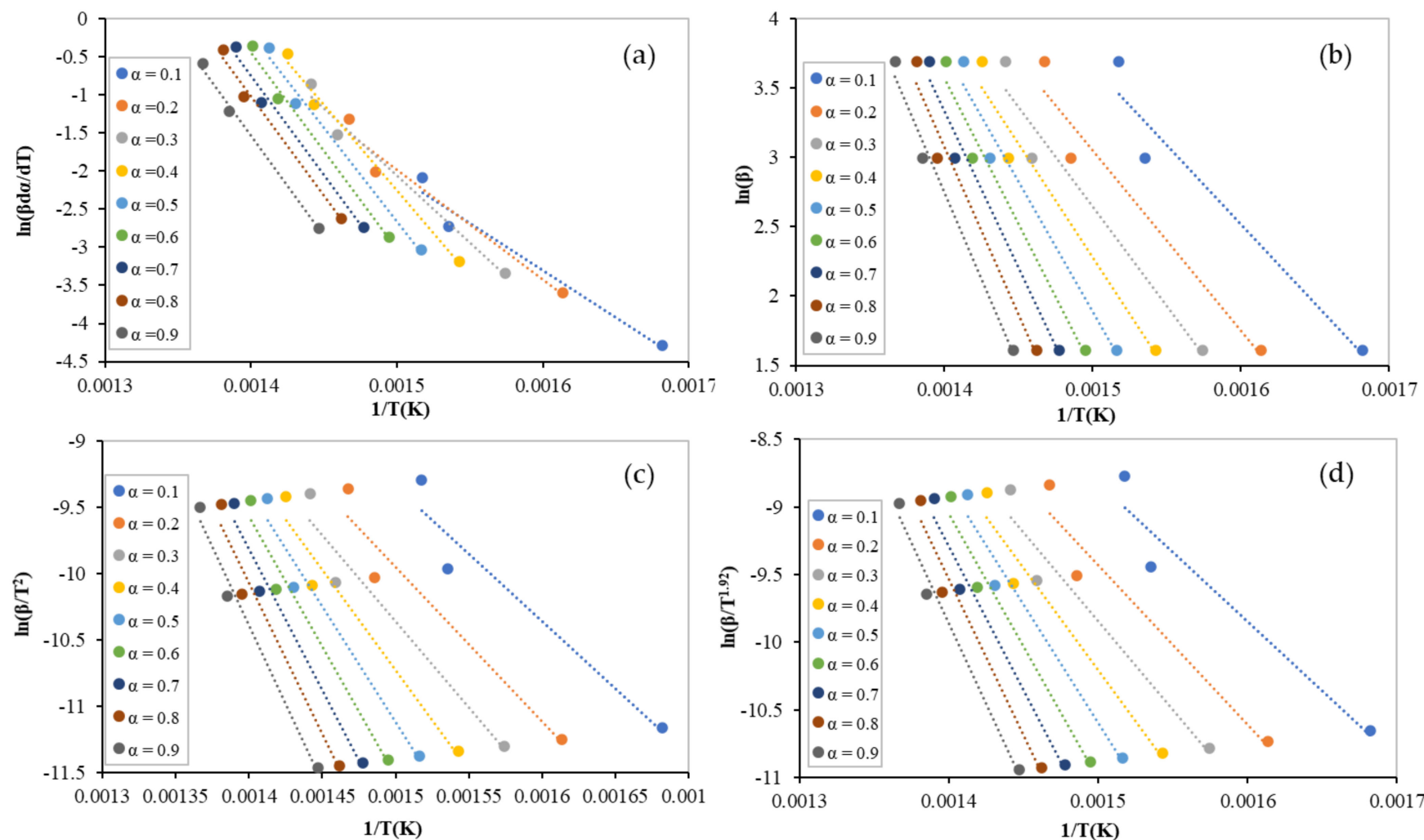

Figure 3. Linear regression lines of binary equi-mass PP and PS mixtures at different conversions by: (a) Freidman; (b) FWO; (c) KAS; and (d) Starink.
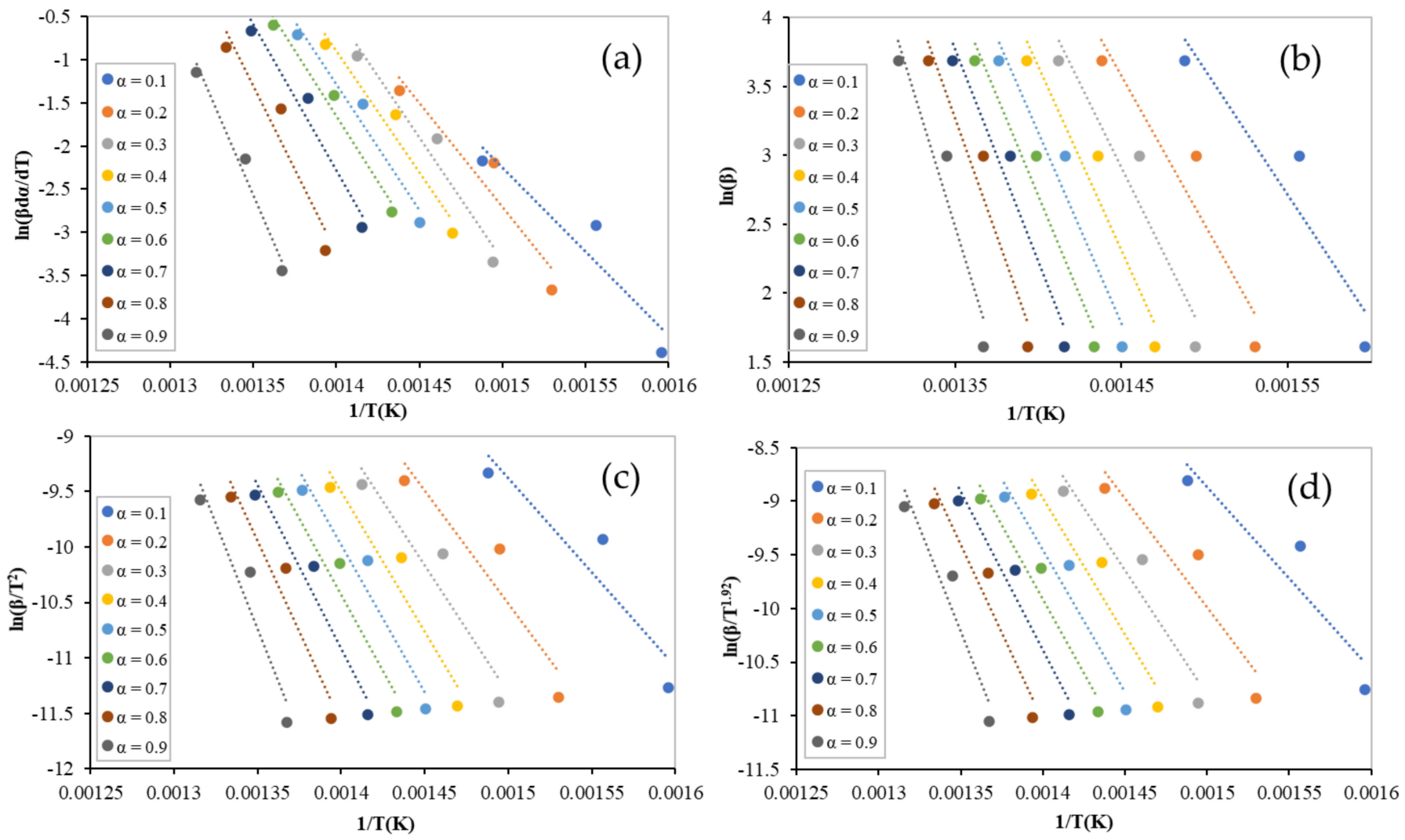

Figure 4. Linear regression lines of ternary equi-mass PP, PS, and LDPE mixtures at different conversions by: (a) Freidman; (b) FWO; (c) KAS; and (d) Starink. 
Table 5. Activation energy of the binary mixtures of PP and PS obtained by different model-free models.

\begin{tabular}{|c|c|c|c|c|c|c|c|c|c|c|}
\hline \multirow{3}{*}{ Conversion } & \multirow{2}{*}{\multicolumn{2}{|c|}{$\begin{array}{c}\text { Differential Method } \\
\text { Friedman } \\
\end{array}$}} & \multicolumn{8}{|c|}{ Integral Methods } \\
\hline & & & \multicolumn{2}{|c|}{ FWO } & \multicolumn{2}{|c|}{ KAS } & \multicolumn{2}{|c|}{ Starink } & \multicolumn{2}{|c|}{ Average Values } \\
\hline & $\begin{array}{c}E_{a} \\
(\mathrm{~kJ} / \mathrm{mol})\end{array}$ & $\mathbf{R}^{2}$ & $\begin{array}{c}E_{a} \\
(\mathrm{~kJ} / \mathrm{mol})\end{array}$ & $\mathbf{R}^{2}$ & $\begin{array}{c}E_{a} \\
(\mathrm{~kJ} / \mathrm{mol})\end{array}$ & $\mathbf{R}^{2}$ & $\begin{array}{c}E_{a} \\
(\mathrm{~kJ} / \mathrm{mol})\end{array}$ & $\mathbf{R}^{2}$ & $\begin{array}{c}E_{a} \\
(\mathrm{~kJ} / \mathrm{mol})\end{array}$ & $\mathbf{R}^{2}$ \\
\hline 0.1 & 103 & 0.9663 & 90 & 0.9458 & 84 & 0.9329 & 85 & 0.9335 & 86 & 0.9374 \\
\hline 0.2 & 120 & 0.9668 & 103 & 0.9525 & 97 & 0.9423 & 97 & 0.9428 & 99 & 0.9459 \\
\hline 0.3 & 146 & 0.9803 & 113 & 0.9562 & 108 & 0.9476 & 109 & 0.948 & 110 & 0.9506 \\
\hline 0.4 & 186 & 0.9911 & 130 & 0.9641 & 125 & 0.9579 & 126 & 0.9582 & 127 & 0.9601 \\
\hline 0.5 & 204 & 0.9887 & 148 & 0.9709 & 145 & 0.9665 & 145 & 0.9667 & 146 & 0.9680 \\
\hline 0.6 & 215 & 0.9915 & 165 & 0.9756 & 163 & 0.9723 & 163 & 0.9724 & 164 & 0.9734 \\
\hline 0.7 & 216 & 0.9852 & 179 & 0.9783 & 176 & 0.9755 & 177 & 0.9756 & 177 & 0.9765 \\
\hline 0.8 & 219 & 0.9888 & 191 & 0.9724 & 189 & 0.9691 & 190 & 0.9693 & 190 & 0.9703 \\
\hline 0.9 & 221 & 0.995 & 199 & 0.9867 & 197 & 0.9852 & 197 & 0.9852 & 198 & 0.9857 \\
\hline Average & 181 & 0.9837 & 146 & 0.9669 & 142 & 0.961 & 143 & 0.9613 & 144 & 0.9631 \\
\hline
\end{tabular}

Table 6. Activation energy of the ternary mixtures of PP, PS, and LDPE obtained by different model-free models.

\begin{tabular}{|c|c|c|c|c|c|c|c|c|c|c|}
\hline \multirow{3}{*}{ Conversion } & \multirow{2}{*}{\multicolumn{2}{|c|}{$\begin{array}{c}\text { Differential Method } \\
\text { Friedman } \\
\end{array}$}} & \multicolumn{8}{|c|}{ Integral Methods } \\
\hline & & & \multicolumn{2}{|c|}{ FWO } & \multicolumn{2}{|c|}{ KAS } & \multicolumn{2}{|c|}{ Starink } & \multicolumn{2}{|c|}{ Average Values } \\
\hline & $\begin{array}{c}E_{a} \\
(\mathrm{~kJ} / \mathrm{mol})\end{array}$ & $\mathbf{R}^{2}$ & $\begin{array}{c}E_{a} \\
(\mathrm{~kJ} / \mathrm{mol})\end{array}$ & $\mathbf{R}^{2}$ & $\begin{array}{c}E_{a} \\
(\mathrm{~kJ} / \mathrm{mol})\end{array}$ & $\mathbf{R}^{2}$ & $\begin{array}{c}E_{a} \\
(\mathrm{~kJ} / \mathrm{mol})\end{array}$ & $\mathbf{R}^{2}$ & $\begin{array}{c}E_{a} \\
(\mathrm{~kJ} / \mathrm{mol})\end{array}$ & $\mathbf{R}^{2}$ \\
\hline 0.1 & 161 & 0.8895 & 144 & 0.8859 & 157 & 0.8696 & 141 & 0.8703 & 147 & 0.8753 \\
\hline 0.2 & 200 & 0.9164 & 171 & 0.898 & 168 & 0.8852 & 169 & 0.8858 & 169 & 0.8897 \\
\hline 0.3 & 236 & 0.9549 & 194 & 0.9164 & 192 & 0.9069 & 193 & 0.9073 & 193 & 0.9102 \\
\hline 0.4 & 235 & 0.9561 & 211 & 0.9363 & 211 & 0.9294 & 211 & 0.9297 & 211 & 0.9318 \\
\hline 0.5 & 243 & 0.9645 & 220 & 0.948 & 220 & 0.9424 & 220 & 0.9427 & 220 & 0.9444 \\
\hline 0.6 & 252 & 0.9731 & 229 & 0.9562 & 229 & 0.9516 & 229 & 0.9518 & 229 & 0.9532 \\
\hline 0.7 & 282 & 0.9608 & 243 & 0.9563 & 244 & 0.952 & 244 & 0.9522 & 244 & 0.9535 \\
\hline 0.8 & 322 & 0.9232 & 271 & 0.9395 & 273 & 0.9342 & 273 & 0.9344 & 272 & 0.9360 \\
\hline 0.9 & 368 & 0.9749 & 312 & 0.9265 & 316 & 0.921 & 316 & 0.9212 & 315 & 0.9229 \\
\hline Average & 255 & 0.9459 & 222 & 0.9292 & 223 & 0.9213 & 222 & 0.9217 & 222 & 0.9241 \\
\hline
\end{tabular}

Although all models performed well to obtain activation energy (check the regression coefficient values $\left(\mathrm{R}^{2}\right)$ presented in Tables 5 and 6 ), the Freidman model provided a slightly different value to the other models. Integral models (FWO, KAS, and Starink) have allow approximations in their mathematical formulations [11].

For the equi-mass binary mixtures (tests 1-3), the average values of the activation energies were 181, $144 \pm 2 \mathrm{~kJ} / \mathrm{mol}$ obtained using the Freidman and integral models, respectively. However, higher values were obtained for the equi-mass ternary plastic mixtures of PP, PS, and LDPE (tests 4-6) (Freidman: $255 \mathrm{~kJ} / \mathrm{mol}$, FWO: $222 \mathrm{~kJ} / \mathrm{mol}$, KAS: $223 \mathrm{~kJ} / \mathrm{mol}$, and Starink: $222 \mathrm{~kJ} / \mathrm{mol}$ ). This can be attributed to LDPE activation energy, which is higher than that of pure PP, PS, and the interaction between the mixture components. In addition, at low conversions $(\alpha<0.3)$, the values of activation energy were almost unstable, caused by errors in the baseline determination [20], or an undetected reaction that had occurred at this low range of temperatures.

\subsection{Reaction Mechanism Determination}

The Coats-Redfern model has been used to obtain the most appropriate reaction mechanism. By plotting $\ln \left[\frac{g(\alpha)}{T^{2}}\right]$ vs. $1 / \mathrm{T}$ for 15 different solid-state reaction mechanisms $(g(\alpha))$ presented in Table 3, activation energy values at different heating rates were obtained (see Tables 7 and 8). Results showed excellent linear regression $\left(R^{2}>0.98\right)$. The average values of the activation energy, obtained using the Coats-Redfern model for different reaction mechanisms, were then compared with the average values obtained by the isoconversional models. 

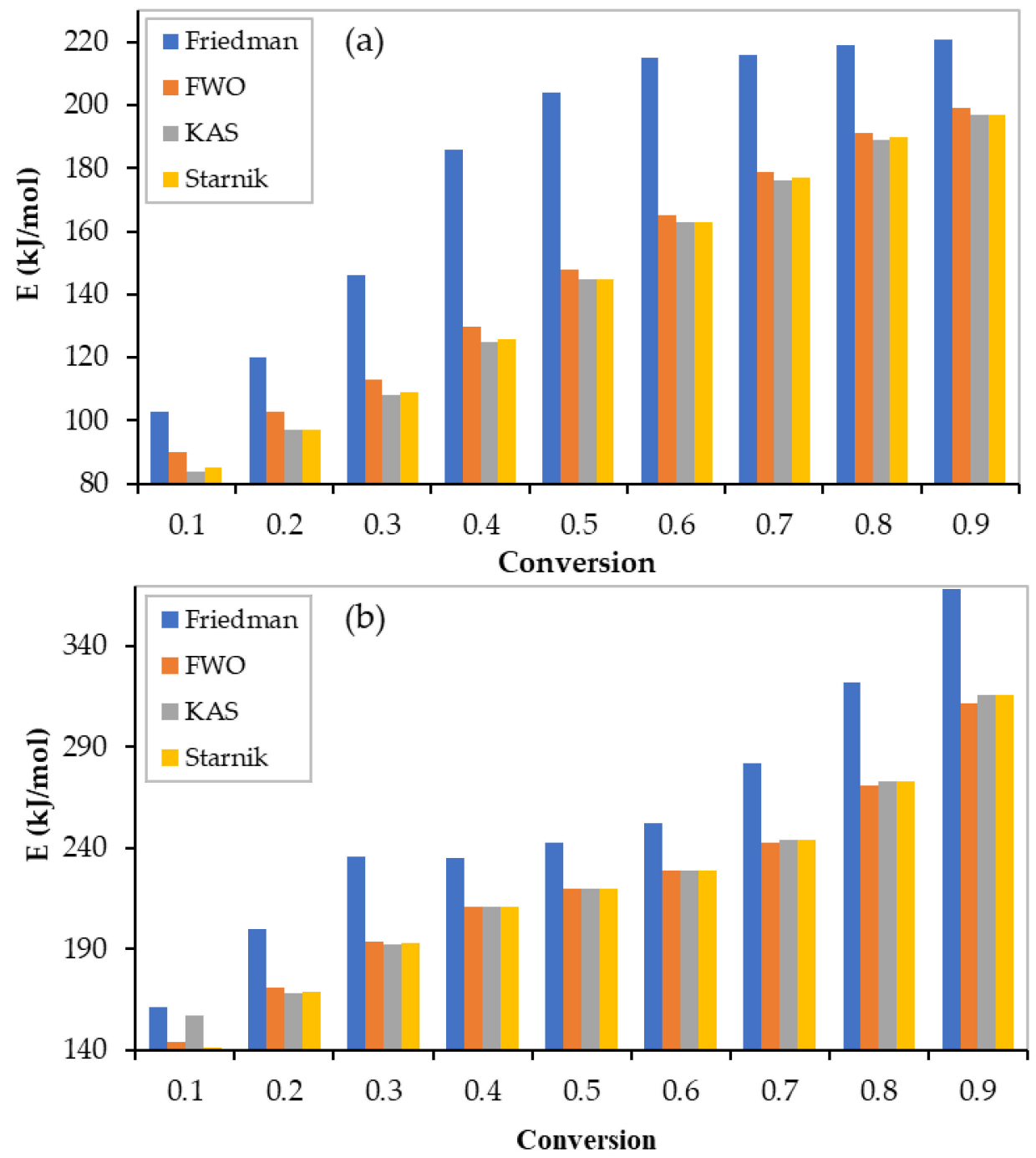

Figure 5. Activation energies obtained by different model-free models: (a) binary mixtures; (b) ternary mixtures.

Table 7. Kinetic parameters of the pyrolysis of plastic mixtures by Coats-Redfern model (tests 1-3).

\begin{tabular}{|c|c|c|c|c|c|c|c|c|}
\hline \multirow{2}{*}{$\begin{array}{c}\text { Reaction } \\
\text { Mechanism }\end{array}$} & \multicolumn{2}{|c|}{$5 \mathrm{~K} / \mathrm{min}$} & \multicolumn{2}{|c|}{$20 \mathrm{~K} / \mathrm{min}$} & \multicolumn{2}{|c|}{$40 \mathrm{~K} / \mathrm{min}$} & \multicolumn{2}{|c|}{ Average Values } \\
\hline & $E_{a}(\mathrm{~kJ} / \mathrm{mol})$ & $R^{2}$ & $E_{a}(\mathrm{~kJ} / \mathrm{mol})$ & $R^{2}$ & $E_{a}(\mathrm{~kJ} / \mathrm{mol})$ & $R^{2}$ & $E_{a}(\mathrm{~kJ} / \mathrm{mol})$ & $\mathbf{R}^{2}$ \\
\hline F1 & 87 & 0.9998 & 182 & 0.9992 & 188 & 0.9997 & 152 & 0.9996 \\
\hline F2 & 110 & 0.9981 & 259 & 0.9933 & 271 & 0.9945 & 213 & 0.9953 \\
\hline F3 & 137 & 0.9941 & 352 & 0.9837 & 372 & 0.9863 & 287 & 0.9880 \\
\hline D1 & 144 & 0.9976 & 258 & 0.995 & 261 & 0.9958 & 221 & 0.9961 \\
\hline D2 & 156 & 0.9989 & 292 & 0.9977 & 297 & 0.9983 & 248 & 0.9983 \\
\hline D3 & 170 & 0.9996 & 333 & 0.9992 & 341 & 0.9997 & 281 & 0.9995 \\
\hline A2 & 38 & 0.9998 & 85 & 0.9991 & 88 & 0.9996 & 70 & 0.9995 \\
\hline A3 & 22 & 0.9997 & 53 & 0.999 & 55 & 0.9996 & 43 & 0.9994 \\
\hline A4 & 14 & 0.9995 & 37 & 0.9989 & 38 & 0.9996 & 30 & 0.9993 \\
\hline R1 & 67 & 0.9972 & 123 & 0.9945 & 125 & 0.9954 & 105 & 0.9957 \\
\hline R2 & 76 & 0.9992 & 151 & 0.9986 & 154 & 0.9992 & 127 & 0.9990 \\
\hline R3 & 80 & 0.9996 & 161 & 0.9992 & 165 & 0.9997 & 135 & 0.9995 \\
\hline P2 & 28 & 0.9957 & 56 & 0.9932 & 56 & 0.9943 & 47 & 0.9944 \\
\hline P3 & 15 & 0.9931 & 33 & 0.9914 & 34 & 0.9928 & 27 & 0.9924 \\
\hline P4 & 9 & 0.9877 & 22 & 0.9888 & 22 & 0.9906 & 18 & 0.9890 \\
\hline
\end{tabular}


Table 8. Kinetic parameters of the pyrolysis of plastic mixtures by Coats-Redfern model (tests 4-6).

\begin{tabular}{|c|c|c|c|c|c|c|c|c|}
\hline \multirow{2}{*}{$\begin{array}{c}\text { Reaction } \\
\text { Mechanism }\end{array}$} & \multicolumn{2}{|c|}{$5 \mathrm{~K} / \mathrm{min}$} & \multicolumn{2}{|c|}{$20 \mathrm{~K} / \mathrm{min}$} & \multicolumn{2}{|c|}{$40 \mathrm{~K} / \mathrm{min}$} & \multicolumn{2}{|c|}{ Average Values } \\
\hline & $E_{a}(\mathrm{~kJ} / \mathrm{mol})$ & $R^{2}$ & $E_{a}(\mathrm{~kJ} / \mathrm{mol})$ & $R^{2}$ & $E_{a}(\mathrm{~kJ} / \mathrm{mol})$ & $R^{2}$ & $E_{a}(\mathrm{~kJ} / \mathrm{mol})$ & $\mathbf{R}^{2}$ \\
\hline F1 & 120 & 0.9996 & 114 & 0.9992 & 143 & 0.9999 & 126 & 0.9996 \\
\hline F2 & 176 & 0.9962 & 152 & 0.9962 & 181 & 0.9993 & 170 & 0.9972 \\
\hline F3 & 244 & 0.9903 & 196 & 0.9924 & 224 & 0.9971 & 221 & 0.9933 \\
\hline D1 & 165 & 0.9955 & 176 & 0.9998 & 233 & 0.998 & 191 & 0.9978 \\
\hline D2 & 190 & 0.9979 & 195 & 1 & 253 & 0.9989 & 213 & 0.9989 \\
\hline D3 & 220 & 0.9994 & 217 & 0.9998 & 275 & 0.9996 & 237 & 0.9996 \\
\hline A2 & 54 & 0.9996 & 51 & 0.9991 & 66 & 0.9999 & 57 & 0.9995 \\
\hline A3 & 32 & 0.9995 & 30 & 0.9989 & 40 & 0.9998 & 34 & 0.9994 \\
\hline A4 & 21 & 0.9993 & 20 & 0.9986 & 27 & 0.9998 & 23 & 0.9992 \\
\hline $\mathrm{R} 1$ & 77 & 0.9948 & 82 & 0.9997 & 111 & 0.9977 & 90 & 0.9974 \\
\hline R2 & 97 & 0.9987 & 97 & 0.9999 & 126 & 0.9993 & 107 & 0.9993 \\
\hline R3 & 104 & 0.9993 & 103 & 0.9998 & 132 & 0.9996 & 113 & 0.9996 \\
\hline P2 & 33 & 0.9926 & 35 & 0.9996 & 49 & 0.9971 & 39 & 0.9964 \\
\hline P3 & 18 & 0.9889 & 20 & 0.9994 & 29 & 0.9961 & 22 & 0.9948 \\
\hline $\mathrm{P} 4$ & 11 & 0.9817 & 12 & 0.999 & 19 & 0.9947 & 14 & 0.9918 \\
\hline
\end{tabular}

As shown in Table 7, the average value of the activation energy obtained by CoatsRedfern for the first-order reaction mechanism (F1) was $152 \mathrm{~kJ} / \mathrm{mole}$, which is the closest value to the average value obtained by the isoconversional models. Thus, the pyrolytic reaction of the equi-mass binary mixtures can be considered a first-order reaction.

Similarly, as presented in Table 8, the third-order reaction (F3) mechanism is the most suitable reaction mechanism for the pyrolysis of the equi-mass ternary mixtures of PS, $\mathrm{PP}$, and LDPE.

Generally, LDPE has a higher activation energy than that of pure PS and PP. The addition of the third polymer (LDPE) resulted in a slower reaction rate (third-order reaction with a higher activation energy) and a higher energy needed for the reaction (higher activation energy). The change in reaction mechanism could also be attributed to the interaction between the mixture components, resulting in a synergistic effect [15].

Practically, the pyrolysis of the binary mixtures of PS and PP needs a lower amount of energy for the reaction to take place (lower $E_{a}$ value) and has a faster reaction rate (firstorder reaction with lower activation energy) when compared to the pyrolysis of ternary mixtures of PS, PP, and LDPE. Therefore, pyrolysis of binary mixtures is preferable.

\subsection{Pre-Exponential Factor Determination}

After the determination of the most suitable reaction mechanism, the pre-exponential factor was obtained using the Friedman, FWO, KAS, and Starink isoconversional models. Tables 9 and 10 illustrate the values of $\ln (A)$ binary and ternary polymer mixtures.

Table 9. Pre-exponential factor of the co-pyrolysis of PS and PP (tests 1-3).

\begin{tabular}{ccccc}
\hline \multirow{2}{*}{ Conversion } & \multicolumn{4}{c}{$\ln (\boldsymbol{A})\left(\mathbf{l n} \mathbf{m i n}^{-\mathbf{1}}\right)$} \\
\cline { 2 - 5 } & Friedman & FWO & KAS & Starink \\
\hline 0.1 & 16.58 & 14.09 & 13.41 & 14.00 \\
0.2 & 19.81 & 16.58 & 15.82 & 16.41 \\
0.3 & 24.70 & 18.72 & 17.92 & 18.52 \\
0.4 & 31.85 & 21.81 & 20.97 & 21.57 \\
0.5 & 34.81 & 25.28 & 24.42 & 25.02 \\
0.6 & 36.71 & 28.39 & 27.50 & 28.10 \\
0.7 & 36.79 & 30.71 & 29.80 & 30.40 \\
0.8 & 37.44 & 32.98 & 32.06 & 32.66 \\
0.9 & 37.96 & 34.28 & 33.34 & 33.94 \\
\hline Average & $\mathbf{3 0 . 7 4}$ & $\mathbf{2 4 . 7 6}$ & $\mathbf{2 3 . 9 2}$ & $\mathbf{2 4 . 5 2}$ \\
\hline
\end{tabular}


Table 10. Pre-exponential factor of the co-pyrolysis of PS, PP, and LDPE (tests 4-6).

\begin{tabular}{ccccc}
\hline \multirow{2}{*}{ Conversion } & \multicolumn{4}{c}{$\ln (\boldsymbol{A})\left(\boldsymbol{l n} \mathbf{m i n}^{-\mathbf{1}}\right)$} \\
\cline { 2 - 5 } & Friedman & FWO & KAS & Starink \\
\hline 0.1 & 27.19 & 23.22 & 23.32 & 23.92 \\
0.2 & 34.13 & 27.96 & 27.99 & 28.59 \\
0.3 & 40.38 & 32.04 & 32.03 & 32.63 \\
0.4 & 40.21 & 35.12 & 35.07 & 35.68 \\
0.5 & 41.66 & 36.57 & 36.50 & 37.10 \\
0.6 & 43.50 & 38.15 & 38.06 & 38.66 \\
0.7 & 48.80 & 40.67 & 40.55 & 41.16 \\
0.8 & 55.84 & 45.41 & 45.26 & 45.87 \\
0.9 & 64.05 & 52.45 & 52.28 & 52.89 \\
\hline Average & $\mathbf{4 3 . 9 7}$ & $\mathbf{3 6 . 8 4}$ & 36.78 & 37.39 \\
\hline
\end{tabular}

To ascertain the suitability of the reaction mechanism, a linear relationship between $\ln (A)$ and $E_{a}$ was established [21]. Figure 6 proves the perfect linear relationship between $\ln (A)$ and $E_{a}$ obtained using all isoconversional models $\left(\mathrm{R}^{2}=0.9959\right)$. This finding confirms the appropriateness of the obtained reaction mechanisms. The triplet kinetic parameters for the pyrolytic reactions of the binary (PS and PP) and ternary (PS, PP, LDPE) mixtures are summarized in Table 11.

To continue this work, an artificial neural network model can be developed to predict the TGA data [22]. In addition, sensitivity analysis can be performed to explore the relationship between the input and output parameters.

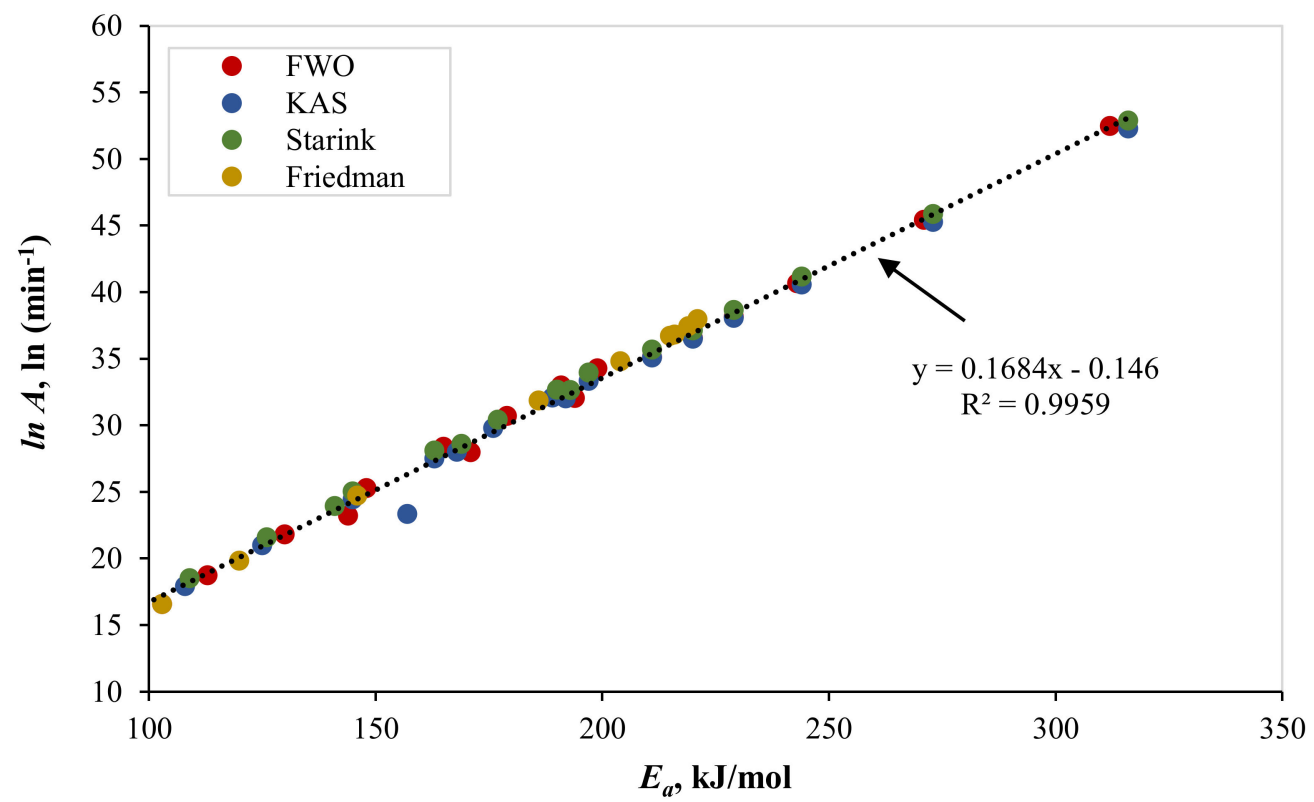

Figure 6. Linear relationship between $\ln A$ and $E a$. 
Table 11. Kinetic parameters of the pyrolysis of mixed polymers.

\begin{tabular}{|c|c|c|c|c|c|}
\hline Mixture & & & & Ternary & \\
\hline Polymers & PS & PP & PS & $\mathrm{PP}$ & LDPE \\
\hline $\begin{array}{l}\text { Composition } \\
\text { (wt \%) }\end{array}$ & 50 & 50 & 33.3 & 33.3 & 33.3 \\
\hline $\begin{array}{c}\text { Reaction } \\
\text { Mechanism }\end{array}$ & & & & F3 & \\
\hline \multicolumn{6}{|c|}{$E_{a}(\mathrm{~kJ} / \mathrm{mol})$} \\
\hline \multicolumn{6}{|l|}{ Differential } \\
\hline $\begin{array}{c}\text { Model } \\
\text { (Friedman) } \\
\text { Integral }\end{array}$ & & & & 255 & \\
\hline $\begin{array}{c}\text { Models } \\
\text { (FWO, KAS, } \\
\text { and Starink) }\end{array}$ & & & & $222.3 \pm 0.6^{*}$ & \\
\hline \multicolumn{6}{|c|}{$\ln A\left(\ln \min ^{-1}\right)$} \\
\hline Differential & & & & & \\
\hline $\begin{array}{c}\text { Model } \\
\text { (Friedman) }\end{array}$ & & & & 43.97 & \\
\hline Integral & & & & & \\
\hline $\begin{array}{c}\text { Models } \\
\text { (FWO, KAS, } \\
\text { and Starink) }\end{array}$ & & & & $37 \pm 0.3$ * & \\
\hline
\end{tabular}

\section{Conclusions}

The pyrolytic kinetics and mechanism of polystyrene (PS), polypropylene (PP), and low-density polyethylene (LDPE) mixtures, which represent almost half of the municipal plastic waste (MPW), have been investigated. This research will contribute significantly to the proper treatment of the huge waste quantity that threatens our environment. Specifically, this work aims to develop a kinetic model that can fully describe the thermal decomposition of plastic mixtures.

In this work, pyrolysis of different plastic mixtures, consisting of PS, PP, and LDPE, was performed using a thermogravimetric analyzer (TGA) at three different heating rates $(5,20$, and $40 \mathrm{~K} / \mathrm{min})$. Four isoconversional models, namely Friedman, Flynn-WallQzawa (FWO), Kissinger-Akahira-Sunose (KAS), and Starink, have been used to obtain the kinetic parameters of the pyrolysis of different plastic mixtures with different compositions. For the equi-mass binary mixtures of PP and PS, the average values of the activation energies were 181, $144 \pm 2 \mathrm{~kJ} / \mathrm{mol}$ obtained by the Freidman and integral (FWO, KAS, and Starink) models, respectively. However, higher values were obtained for the equi-mass ternary plastic mixtures of PP, PS, and LDPE (Freidman: $255 \mathrm{~kJ} / \mathrm{mol}$, FWO: $222 \mathrm{~kJ} / \mathrm{mol}$, KAS: $223 \mathrm{~kJ} / \mathrm{mol}$, and Starink: $222 \mathrm{~kJ} / \mathrm{mol}$ ). Then, the best suitable reaction mechanism was obtained using the Coats-Redfern model. The results confirm that the most controlling reaction mechanisms obey the first-order and third-order reactions for the pyrolysis of the equi-mass binary (PS and PP) and equi-mass ternary (PS, PP, and LDPE) mixtures, respectively. Finally, the values of the pre-exponential factor were obtained using the four isoconversional models, and the linear relationship between $\ln A$, and the obtained activation energy was confirmed. The results reveal that the pyrolysis of binary mixtures is preferable, with lower energy consumption and a faster reaction rate.

Author Contributions: Both authors contributed significantly to the completion of this article, but they had different roles in all aspects. Conceptualization, I.D. and M.A.-Y.; Data curation, I.D. and M.A.-Y.; Formal analysis, I.D. and M.A.-Y.; Funding acquisition, I.D.; Investigation, I.D. and M.A.-Y.; Methodology, I.D. and M.A.-Y.; Project administration, I.D. and M.A.-Y.; Software, I.D. and M.A.-Y.; Validation, M.A.-Y.; Visualization, I.D. and M.A.-Y.; Writing—original draft, I.D. and M.A.-Y.; 
Writing-review and editing, M.A.-Y. All authors have read and agreed to the published version of the manuscript.

Funding: This research and the APC were funded by the Deanship of Scientific Research at King Faisal University, Saudi Arabia, Nasher Track 2020 (Grant No. 206051).

Institutional Review Board Statement: Not applicable.

Informed Consent Statement: Not applicable.

Data Availability Statement: The data presented in this study are available in the article.

Acknowledgments: The authors gratefully thank the Deanship of Scientific Research at King Faisal University (Saudi Arabia) for financial funding under Nasher Track 2020 (Grant No. 206051).

Conflicts of Interest: The authors declare no conflict of interest.

\section{References}

1. Diaz Silvarrey, L.S.; Phan, A.N. Kinetic study of municipal plastic waste. Int. J. Hydrog. Energy 2016, 41, 16352-16364. [CrossRef]

2. Thompson, R.C.; Moore, C.J.; Fvom Saal, F.S.; Swan, S.H. Plastics, the environment and human health: Current consensus and future trends. Philos. Trans. R. Soc. B Biol. Sci. 2009, 364, 2153-2166. [CrossRef] [PubMed]

3. Hopewell, J.; Dvorak, R.; Kosior, E. Plastics recycling: Challenges and opportunities. Philos. Trans. R. Soc. B Biol. Sci. 2009, 364, 2115-2126. [CrossRef]

4. Ahmed, I.I.; Gupta, A.K. Hydrogen production from polystyrene pyrolysis and gasification: Characteristics and kinetics. Int. J. Hydrog. Energy 2009, 34, 6253-6264. [CrossRef]

5. Arandes, J.; Abajo, I.; Lopez-Valerio, D.; Fernandez, I.; Azkoiti, M.J.; Olazar, M.; Bilbao, J. Transformation of several plastic wastes into fuels by catalytic cracking. Ind. Eng. Chem. Res. 1997, 36, 4523-4529. [CrossRef]

6. Kaminsky, W.; Schlesselmann, B.; Simon, C.M. Thermal degradation of mixed plastic waste to aromatic and gas. Poly. Degrad. Stab. 1996, 53, 189-197. [CrossRef]

7. Aguado, J.; Serrano, D.P.; San Miguel, G.; Castro, M.C.; Madrid, S. Feedstock recycling of polyethylene in a two-step thermocatalytic reaction system. J. Anal. Appl. Pyrolysis 2007, 79, 415-423. [CrossRef]

8. Rasul Jan, M.; Shah, J.; Gulab, H. Catalytic conversion of waste high-density polyethylene into useful hydrocarbons. Fuel 2013, 105, 595-602. [CrossRef]

9. Wu, C.H.; Chang, C.Y.; Hor, J.L.; Shih, S.M.; Chen, L.W.; Chang, F.W. On The Thermal Treatment of Plastic Mixtures of MSW: Pyrolysis Kinetics. Waste Manag. 1993, 13, 221-235. [CrossRef]

10. Chowlu, A.C.K.; Reddy, P.K.; Ghoshal, A.K. Pyrolytic decomposition and model-free kinetics analysis of mixture of polypropylene (PP) and low-density polyethylene (LDPE). Thermochim. Acta 2009, 485, 20-25. [CrossRef]

11. Aboulkas, A.; El Harfi, K.; Bouadili, A. Thermal degradation behaviors of polyethylene and polypropylene. Part I: Pyrolysis Kinetics and Mechanisms. Energy Convers. Manag. 2010, 51, 1363-1369. [CrossRef]

12. Yu, J.; Sun, L.; Ma, C.; Qiao, Y.; Yao, H. Thermal degradation of PVC: A review. Waste Manag. 2016, 48, 300-314. [CrossRef] [PubMed]

13. Anene, A.F.; Fredriksen, S.B.; Sætre, K.A.; Tokheim, L.A. Experimental Study of Thermal and Catalytic Pyrolysis of Plastic Waste Components. Sustainability 2018, 10, 3979. [CrossRef]

14. Mumbach, G.D.; Alves, J.L.F.; Silva, J.C.G.D.; Sena, R.F.D.; Marangoni, C.; Machado, R.A.F.; Bolzan, A. Thermal investigation of plastic solid waste pyrolysis via the deconvolution technique using the asymmetric double sigmoidal function: Determination of the kinetic triplet, thermodynamic parameters, thermal lifetime and pyrolytic oil composition for clean energy recovery. Energy Convers. Manag. 2019, 200, 112031. [CrossRef]

15. Dubdub, I.; Al-Yaari, M. Pyrolysis of mixed plastic waste: I. Kinetic study. Materials 2020, 13, 4912. [CrossRef] [PubMed]

16. Dubdub, I.; Al-Yaari, M. Pyrolysis of low density polyethylene: Kinetic study using TGA data and ANN prediction. Polymers 2020, 12, 891. [CrossRef] [PubMed]

17. Al-Yaari, M.; Dubdub, I. Application of Artificial Neural Networks to Predict the Catalytic Pyrolysis of HDPE Using NonIsothermal TGA Data. Polymers 2020, 12, 1813. [CrossRef]

18. Vyazovkin, S.; Wight, C.A. Model-free and model-fitting approaches to kinetic analysis of isothermal and nonisothermal data. Thermochim. Acta 1999, 340, 53-68. [CrossRef]

19. Özsin, G.; Pütün, A.E. TGA/MS/FT-IR study for kinetic evaluation and evolved gas analysis of a biomass/PVC co-pyrolysis process. Energy Convers. Manag. 2019, 182, 143-153. [CrossRef]

20. Xu, F.; Wang, B.; Yang, D.; Hao, J.; Qiao, Y.; Tian, Y. Thermal degradation of typical plastics under high heating rate conditions by TG-FTIR: Pyrolysis behaviors and kinetic analysis. Energy Convers. Manag. 2018, 171, 1106-1115. [CrossRef]

21. Chen, R.; Li, Q.; Zhang, Y.; Xu, X.; Zhang, D. Pyrolysis kinetics and mechanism of typical industrial non-tyre rubber wastes by peak-differentiating analysis and multi kinetics methods. Fuel 2019, 235, 1224-1237. [CrossRef]

22. Dubdub, I.; Al-Yaari, M. Pyrolysis of Mixed Plastic Waste: II. An Artificial Neural Networks Prediction and Sensitivity Analysis. Appl. Sci. 2021, 11, 8456. [CrossRef] 